\title{
Budaya Timur Tengah Pasca Arab Spring (Analisis Deskriptif Budaya Arab)
}

\author{
Zulkarnen $^{1}$ \\ ${ }^{1}$ Program Studi Sastra Arab, Fakultas Sastra, Universitas Al Azhar Indonesia, Jalan \\ Sisingamangaraja, Kompleks Masjid Agung Al Azhar, Kebayoran Baru, Jakarta 12110 \\ Penulis untuk Korespondensi/E-mail: zulkarnen@uai.ac.id
}

\begin{abstract}
Abstrak - Musim Semi Arab adalah fenomena yang terjadi di negara-negara Timur Tengah yang timbul dari dinamika sosial yang menginginkan orde baru yang dapat mengubah keadaan suatu negara dalam bentuk protes atau pemberontakan yang dilakukan oleh pro-demokrasi di Timur Tengah dan Afrika Utara melawan rezim otoriter di wilayah yang dimulai sekitar tahun 2010 hingga 2011. Dalam studi Budaya Arab bukanlah fenomena baru di Timur Tengah, karena Hitti (2006) mengatakan bahwa budaya Arab egaliter dan geografi gurun tandus khas adalah faktor yang membentuk karakter dan kepribadian utama yang keras dan pantang menyerah. Analisis deskriptif tentang pendekatan kualitatif terhadap budaya Arab fenomena Musim Semi Arab sangat langka sehingga, penulis berharap tulisan ini bisa menggambarkan studi budaya Arab dalam fenomena Musim Semi Arab. Orde baru yang merupakan harapan utama dinamika sosial masih jauh dari harapan, sehingga dalam tulisan ini penulis memberikan alternatif untuk pembentukan sebuah teori berbasis masyarakat regional dan berbasis masyarakat masyarakat Arab pasca Islam.
\end{abstract}

\section{Kata Kunci - Arab Spring, Dinamik, Budaya, Arab}

Abstract - Arab Spring is a phenomenon that occurs in the countries of the Middle East arising from a social dynamic who want a new order that can change the state of a country in the form of protest or rebellion committed by the pro-democracy in the Middle East and North Africa against authoritarian regimes in the region that started around the year 2010 up to 2011. In the Arab Cultural studies is not a new phenomenon in the Middle East, because Hitti (2006) says that Arab culture egalitarian and typical barren desert geography is a factor which form the main character and personality are hard and unyielding. Descriptive analysis of the qualitative approach to the Arab culture of the Arab Spring phenomenon is so rare that, the author hopes this paper can describe the Arab culture studies in the phenomenon of the Arab Spring. New order which is the main hope of social dynamics is still far from the hope, so in this paper the authors provide an alternative to the establishment of a regional and community based theory of post-Islamic Arab society institutions.

Keywords - Arab Spring, Dynamics, Culture, Arab

\section{PENDAHULUAN}

$\mathrm{L}$ ahirnya budaya demokrasi yang lebih baik $\lambda_{\text {dan }}$ berjatuhannya para pemimpin otoriter menjadikan istilah baru "The Arab Spring" (Musim Semi Arab) yang terkait dinamika yang terjadi di kawasan Timur Tengah (Sahide, 2013: 227), terutama negara-negara Arab, dimulai sejak tahun 2010 sampai dengan 2011 ditandai dengan kebangkitan harapan akan masa depan yang lebih baik.

Arab Spring merupakan fenomena yang timbul dari sebuah dinamika sosial yang menginginkan adanya sebuah tatanan baru yang dapat merubah keadaan sebuah negara yang berupa gelombang protes atau bahkan pemberontakan yang dilakukan oleh masyarakat pro-demokrasi di Timur Tengah 
dan Afrika Utara terhadap rezim-rezim otoriter di wilayah tersebut yang dimulai dari Tunisia, Zein Al-Abidin Ben Ali (Ben Ali), kemudian merambat ke Mesir yang melengserkan Hosni Mubarak, terus menyeberang ke Libya, yang mengakhiri pemerintahan Moammar Khadafy yang sudah berlangsung kurang lebih 40 tahun lamanya.

Dalam kajian budaya Arab. fenomena ini bukanlah hal baru di Timur tengah, karena Hitti (2006) mengatakan bahwa budaya Arab yang egaliter dan geografi tandus khas padang pasir merupakan faktor utama yang membentuk karakter dan kepribadian yang keras dan pantang menyerah.

Pendekatan analisis Deskriptif kualitatif budaya Arab dari Fenomena Arab Spring masih sangat langka, sehingga penulis mengharapkan makalah ini dapat mendeskripsikan kajian budaya Arab dalam fenomena Arab Spring.

Tatanan baru yang merupakan harapan utama dari dinamika sosial ini masih jauh panggang dari api, sehingga dalam makalah ini penulis memberikan alternatif pembentukan sebuah kawasan dan masyarakat berdasarkan teori pranata masyarakat Arab pasca Islam.

\section{KERANGKA TEORI}

\section{Fenomena}

Fenomena adalah kenyataan yang menampakkan diri (Hardiman, 2007: 28) seperti yang penulis kutip dari KBBI online yang mendefinisikan Fenomena adalah hal-hal yg dapat disaksikan dengan pancaindra dan dapat diterangkan serta dinilai secara ilmiah.

Kant kemudian membedakan antara fenomena dan nomena. Wilayah fenomena menurutnya masih dapat diketahui oleh akal, sedangkan wilayah nomena yang tidak dapat diketahui. Tuhan adalah wilayah nomena ini. Sehingga Fenomena adalah gejala yang tampak dan dapat diamati, sedangkan nomena adalah mengukur Tuhan dengan akal (meminjam pemikiran Ibn Khaldun) sama dengan menimbang emas gunung dengan timbangan emas (Sukardi, 2003: 67) .
Perlu dicermati di sini adalah fenomena tidak sama dengan masalah. Fenomena adalah fakta yang kita temukan di lapangan. Untuk mengetahui apa masalah yang sebenarnya terjadi, kita perlu mengidentifikasi penyebab masalah untuk berbagai masalah (Rangkuti, 2011: 53). Karena Fenomena adalah entitas yang diam, di mana maknanya ditentukan oleh sudut pandang, termasuk kepentingan orang yang melihatnya (Bagir, 2005)

Penulis dalam makalah ini menggunakan definisi Fenomena yang berarti berpikir fenomenologis yaitu mencoba memahami dan bukannya mempertanyakan mengapa suatu kelompok manusia berpikir dan bertindak sesuatu. (Jatmika, 2009: 64).

\section{Dinamika}

Kelompok sosial selalu mengalami perubahan. Hal ini terjadi karena setiap kelompok tidaklah bersifat statis atau stagnan. Tahapan demi tahapan perkembangan kelompok sosial dan perubahannya disebut dinamika kelompok sosial (Huntington, 1996: 29).

Dinamika dalam KBBI berarti gerak (dari dalam); tenaga yang menggerakkan; semangat. Sementara dinamika kelompok merupakan gerak atau kekuatan yang dimiliki sekumpulan orang dalam masyarakat yang dapat menimbulkan perubahan dalam tata hidup masyarakat yang bersangkutan dan dinamika sosial diartikan sebagai gerak masyarakat secara terus-menerus yang menimbulkan perubahan dalam tata hidup masyarakat yang bersangkutan.

Pengertian dinamika kelompok sosial dapat diartikan sebagai sebuah proses perubahan dan perkembangan akibat adanya hubungan beberapa orang atau kelompok dalam masyarakat yang bersifat terus menerus yang kemudian memiliki kekuatan untuk menimbulkan perubahan dari dalam.

Ruth Benedict (2005) mengungkapkan terdapat pokok persoalan (aspek) yang dipelajari dalam dinamika kelompok sosial, diantaranya:

1. Kohesi atau persatuan

Dalam persoalan kohesi akan terlihat tingkah laku para anggota dalam suatu kelompok, seperti proses pengelompokan, 
intensitas anggota, arah pilihan dan nilainilai dalam kelompok.

2. Motif atau dorongan

Persoalan motif berkisar pada perhatian anggota terhadap kehidupan kelompok, seperti kesatuan kelompok, tujuan bersama dan orientasi diri terhadap kelompok.

3. Struktur

Persoalan ini terlihat pada bentuk pengelompokan, bentuk hubungan, perbedaan kedudukan antar anggota, dan pembagian tugas.

4. Pimpinan

Persoalan pimpinan sangat penting pada kehidupan kelompok sosial, hal ini terlihat pada bentuk-bentuk kepemimpinan, tugas pimpinan dan sistem kepemimpinan.

5. Perkembangan kelompok

Persoalan perkembangan kelompok dapat dilihat dari perubahan dalam kelompok, perpecahan kelompok, keinginan anggota untuk tetap berada dalam kelompok dan sebagainya.

Saat ini banyak pihak menyadari pentingnya mempelajari dinamika kelompok sosial karena alasan berikut:

1. Kelompok sosial merupakan kesatuankesatuan sosial yang selalu ada dalam setiap masyarakat.

2. Dinamika kelompok sosial berkaitan dengan perubahan sosial dan kebudayaan masyarakat.

\section{Faktor-faktor pendorong dinamika kelompok sosial}

Adanya kelompok sosial yang mengalami perkembangan maupun perubahan selalu berkaitan dengan faktor pendorong. Adapun faktor-faktor yang menyebabkannya sebagai berikut:

1. Faktor Pendorong Dinamika Kelompok Sosial dari Luar (ekstern):

Faktor pendorong dari luar kelompok merupakan pengaruh luar yang menyebabkan berkembangnya suatu kelompok sosial, di antaranya sebagai berikut:
a. Perubahan situasi sosial
b. Perubahan situasi ekonomi
c. Perubahan situasi politik

2. Faktor Pendorong Dinamika Kelompok Sosial yang berasal dari Dalam (Intern): Faktor ini merupakan kondisi di dalam sebuah kelompok sosial yang menyebabkan perkembangan suatu kelompok sosial, di antaranya sebagai berikut:

a. Adanya konflik antar anggota kelompok

b. Adanya perbedaan kepentingan

c. Adanya Perbedaan paham

\section{Proses perkembangan berbagai kelompok sosial.}

Dinamika kelompok sosial tidak lepas dari perkembangan kelompok sosial dari kelompok yang sederhana menjadi kelompok yang kompleks. Perkembangan kelompok sosial dalam masyarakat dimulai dari kelompok sosial yang paling homogen dan sederhana yaitu kelompok kekerabatan, yang kemudian berkembang menjadi kelompok sosial yang kompleks yaitu masyarakat perkotaan sehingga dapat dilihat sebagai berikut:

\section{a. Kelompok Kekerabatan}

Keluarga merupakan kelompok sosial terkecil dalam masyarakat. Keluarga inti yang terdiri dari ayah, ibu dan anak-anaknya yang belum menikah. Dari keluarga inti berkembang menjadi keluarga besar (extended family) yang disebut kelompok kekerabatan. Dalam kelompok kekerabatan terdapat hubungan darah atau hubungan persaudaraan. Kelompok kekerabatan ini merupakan cikal bakal terbentuknya masyarakat.

Dalam kelompok kekerabatan nilai-nilai tradisional masih dijunjung tinggi sehingga kehidupan kelompok terpusat pada tradisi kebudayaan yang telah dipelihara secara turun-menurun. Menurut Huntington (1996) kemungkinan mengubah tradisi kebudayaan yang telah dipelihara secara turun temurun memang sulit, tetapi melalui proses inovasi khususnya dalam bidang ekonomi dan politik yang dilakukan secara bertahap, perubahan-perubahan dalam kelompok kekerabatan dapat terjadi dalam waktu yang cukup lama.

\section{b. Kelompok Okupasional}

Kelompok kekerabatan merupakan masyarakat homogen yang menganut nilainilai, norma-norma, ataupun pola tingkah laku yang relatif sama sehingga pembagian kerja dilakukan secara sederhana 
berlandaskan pada tradisi dan perbedaan jenis kelamin.

Dalam masyarakat tradisional belum terdapat spesialisasi pekerjaan, tetapi tidak ada satu masyarakat pun yang benar-benar tertutup dari pengaruh luar. Ketika kelompok kekerabatan mendapat pengaruh dari luar, maka kelompok tersebut berkembang menjadi suatu masyarakat yang heterogen. Dalam masyarakat yang heterogen timbul spesifikasi pekerjaan atas dasar bakat dan kemampuan.

Pada perkembangan selanjutnya, spesifikasi semakin berkembang lebih khusus lagi, munculnya berbagai industri menuntut para pekerja bertanggung jawab pada satu unsur tertentu saja sehingga para pekerja semakin ahli dalam bidang tertentu dan kurang mampu mengerjakan pekerjaan lainnya.

Ketika masyarakat semakin maju, spesifikasi dikembangkan secara ilmiah melalui lembaga-lembaga pendidikan tertentu sehingga menghasilkan orang-orang yang ahli dalam ilmu-ilmu tertentu. Oleh sebab itu, munculah kelompok-kelompok profesi (kelompok okupasional) yang terdiri dari kalangan professional yang memiliki etika profesi.

\section{c. Kelompok Volunter}

Berkembangnya komunikasi dan media online secara luas dan cepat menyebabkan tidak ada satu masyarakat pun yang benarbenar tertutup terhadap dunia luar. Akibatnya, heterogenitas masyarakat semakin luas. Dengan semakin berkembangnya suatu masyarakat, maka tidak semua kebutuhan para anggota masyarakat terpenuhi. Oleh karena itu, muncullah kelompok-kelompok volunteer.

Kelompok volunteer terdiri dari orang-orang yang mempunyai kepentingan-kepentingan yang sama, tetapi tidak mendapatkan perhatian dari masyarakat yang semakin luas daya jangkaunya. Kelompok volunteer tersebut memenuhi kebutuhan-kebutuhan para anggotanya secara mandiri tanpa mengganggu kepentingan masyarakat umum. Kelompok volunteer dapat berkembang menjadi kelompok yang mantap karena diakui oleh masyarakat umum.

\section{Pranata Masyarakat}

Teori-teori di atas menggambarkan bahwa negara-negara di kawasan Timur Tengah seyogyanya memulai kembali dari awal, melalui makalah ini penulis berharap dapat memberikan kontribusi dalam mengembalikan stabilitas di kawasan tersebut sehingga tercipta situasi yang damai, aman dan harmonis.

Sebagaimana dapat kita pahami bersama sebelum terjadinya sebuah kebudayaan yang mapan dalam sebuah tatanan masyarakat perlu dilakukan langkah-langkah terobosan guna memperoleh kesepahaman bersama, di mana kesepahaman inilah yang kemudian disebut sebagai pranata yang berlaku dan disepakati bersama oleh seluruh masyarakat.

Pranata sendiri memiliki definisi sebagai sistem tingkah laku sosial yang bersifat resmi serta adat-istiadat dan norma yang mengatur tingkah laku itu, dan seluruh perlengkapannya guna memenuhi berbagai kompleks kebutuhan manusia dalam masyarakat; institusi (KBBI).

Dari definisi di atas kemudian dikembangkan definisi pranata oleh para ahli diantaranya yang penulis kutip dalam makalah ini adalah pendapat Horton dan Hunt (1980: 198), yang menyatakan bahwa pranata sosial adalah suatu sistem norma untuk mencapai suatu tujuan atau kegiatan yang oleh masyarakat di pandang penting. pranata sosial dalam setiap pembahasan selalu mengenai tiga kata kunci yaitu:

1. nilai dan norma

2. pola prilaku yang menjadi prosedur umum; dan

3. sistem hubungan, yaitu institusiinstitusi yang berlaku dan digunakan untuk melaksanakan perilaku sesuai dengan prosedur umum yang berlaku dan disepakati oleh masing-masing pihak.

\section{PEMBAHASAN}

Arab Spring mulai giat diperbincangkan oleh para ahli ketika terjadi berbagai peristiwa yang mengguncang bahkan meruntuhkan rezim berkuasa di beberapa negara di timurtengah. 
Peristiwa yang terjadi pada tahun 2010 sampai dengan 2011 ditandai dengan berbagai protes terkait dengan kondisi negara yang dianggap tidak memberikan kontribusi yang nyata terhadap tuntutan warga negaranya.

Gelombang protes ini terus berlanjut dalam bentuk demontrasi kemudian berkembang menjadi konflik bersenjata, di mana negara bertarung melawan rakyatnya sendiri yang mengangkat senjata dengan membentuk aliansi-aliansi (kelompok-kelompok) diantara mereka yaitu menggerakkan kebangkitan harapan akan lahirnya sistem politik baru yang lebih baik.

Arab Spring merupakan sebuah fenomena merebaknya revolusi demokrasi di dunia Arab. Peristiwa ini diawali oleh Tunisia pada sekitar pertengahan tahun 2010, kemudian merambah ke negara-negara lain, seperti Mesir, dan Syiria yang hingga saat ini masih bergejolak.

Nama Arab Spring sendiri berarti musim semi di Arab. Kata ini merujuk pada peristiwa 1848 (Rubin, 1998), yang mana terjadi revolusi rakyat di sebagian wilayah Arab. Dalam konteks Arab Spring, sesuatu yang bersemi adalah nilai-nilai demokrasi yang kemudian menyebar dengan efek domino ke negaranegara sekitarnya.

Tetapi pendapat Rubin di atas dibantah oleh Sahrasad (2012) yang menyatakan bahwa demokratisasi yang dipaksakan oleh negaranegara barat di negara-negara timur tengah tidak bisa terealisasi dengan baik, sehingga Sihbudi (2007: 135) mengatakan Amerika Serikat harus menerapkan politik standar ganda dalam memberikan dukungan ke sejumlah negara di kawasan ini.

Hal inilah yang menurut penulis layak untuk dikaji secara budaya karena kajian-kajian dengan pendekatan politik maupun hubungan internasional menemui jalan buntu dalam analisis yang tepat dan lebih predictable.

Sementara timur tengah terus menggelora dan huru-hara ini terus menambah deretan korban manusia dan sejumlah masalah bagi dunia internasional seperti masalah pengungsi yang sampai hari ini belum ada penyelesaiannya.
Fenomena yang timbul dari sebuah dinamika kelompok sosial ini menginginkan adanya tatanan baru yang dapat merubah keadaan sebuah negara di kawasan Timur Tengah dan Afrika Utara terhadap rezim-rezim otoriter di wilayah tersebut yang dimulai dari Tunisia, Zein Al-Abidin Ben Ali (Ben Ali), kemudian merambat ke Mesir yang melengserkan Hosni Mubarak, terus menyeberang ke Libya, yang mengakhiri pemerintahan Moammar Khadafy.

Dalam kajian budaya Arab. fenomena ini bukanlah sesuatu yang baru di kawasan yang memiliki nilai strategis bagi negara-negara maju ini, Hitti (2006) mengatakan bahwa budaya masyarakat Arab yang egaliter (kesetaraan) dan pantang untuk tunduk kepada manusia kecuali hanya kepada sang Maha Pemberi dan Maha Pelindung menjadi faktor utama penyebab sering terjadinya dinamika kelompok sosial di wilayah ini.

Geografi yang tandus dan gersang khas padang pasir merupakan faktor berikutnya yang membentuk karakter dan kepribadian serta sikap yang pantang menyerah bagi individu yang sanggup bertahan hidup di kawasan ini makin mempersulit setiap upaya untuk membangun stabilitas kawasan yang memiliki cadangan emas hitam terbesar di dunia.

Budaya Arab dari Fenomena Arab Spring masih sangat langka, seperti pada kerangka teori di atas dapat kita pahami bahwa kelompok sosial selalu mengalami perubahan. Hal ini terjadi karena setiap kelompok tidaklah bersifat statis atau stagnan. Tahapan demi tahapan perkembangan kelompok sosial dan perubahannya disebut dinamika kelompok sosial.

Bila kita melihat budaya Arab yang sangat menjunjung tinggi nilai kekerabatan dan hubungan darah maka, dari fenomena Arab Spring telah terjadi pergeseran menjadi komunitas atau kelompok yang memiliki satu pemahaman bersama, maka saat ini bukan lagi suku atau kabilah yang bermain tetapi merupakan sebuah kelompok sosial.

Huntington (1996: 29) sendiri menggunakan kata "force" untuk mendefinisikan sebuah dinamika kelompok sosial yang diterjemahkan sebagai sebuah proses perubahan dan perkembangan akibat adanya hubungan 
beberapa orang atau kelompok dalam masyarakat yang bersifat terus menerus yang kemudian memiliki kekuatan untuk menimbulkan perubahan dari dalam.

Sehingga di sini penulis melihat bahwa menjadi syarat sebuah dinamika untuk melakukan proses mengumpulkan kekuatan sebelum terjadi sebuah perubahan, seperti yang dapat kita cermati dari kasus Arab Spring yang terjadi di Mesir, maka kelompok Ikhwanul Muslimin bukanlah pemain baru dalam kancah perpolitikan Mesir yang telah melakukan penghimpunan kekuatan selama puluhan tahun.

Ruth Benedict (2005) kemudian mengungkapkan aspek yang harus dimiliki yaitu kohesi atau persatuan seperti sudah kami sampaikan di atas bahwa terjadi pergeseran dalam budaya Arab dari persatuan suku atau hubungan darah menjadi persatuan kelompok.

Motif atau dorongan menjadi aspek selanjutnya yang harus kita perhatikan terkait dengan kesatuan kelompok, tujuan bersama dan orientasi diri terhadap kelompok-kelompok yang berperan pasca Arab Spring seperti ISIS yang malah menjadi masalah baru.

Struktur, pimpinan, perkembangan kelompok tidak penulis bahas pada makalah ini karena masih belum terlihat dengan jelas konsep seperti apa yang akan lahir dari dinamika kelompok sosial ini, sangat berbeda dengan revolusi Iran pada 1979 yang sedari awal sudah mempropagandakan konsep politik Republik Islam Iran.

Banyak pihak saat ini menyadari pentingnya mempelajari dinamika kelompok sosial karena kelompok sosial merupakan kesatuan-kesatuan sosial yang selalu ada dalam setiap masyarakat dan dinamika kelompok sosial berkaitan dengan perubahan sosial dan kebudayaan masyarakat. Khususnya dalam kasus pasca Arab Spring dapat terlihat peranan kelompokkelompok ini semakin dominan yang mengakibatkan position bargaining karena kekosongan tampuk pemerintahan.

Adanya kelompok sosial yang mengalami perkembangan maupun perubahan selalu berkaitan dengan faktor pendorong. penyebabnya dapat dari luar (ekstern) seperti perubahan situasi sosial, perubahan situasi ekonomi, dan perubahan situasi politik yang sangat jelas terlihat di Libya setelah wafatnya Moammar Khadafy. Maupun yang berasal dari Dalam (Intern) seperti adanya konflik antar anggota kelompok, adanya perbedaan kepentingan dan adanya perbedaan paham seperti sudah dikemukakan di atas bahwa ada ketidakpuasan yang menghimpun kekuatan dan mulai melancarkan protes dan akhirnya mengakhiri pemerintahan atau rezim yang sedang berkuasa.

Dinamika kelompok sosial tidak lepas dari perkembangan kelompok sosial yang dapat kita lihat dari fenomena Arab Spring perkembangan dari kelompok yang sederhana menjadi kelompok yang kompleks. Kelompok kekerabatan merupakan ciri dalam budaya Arab. Mereka masih menjunjung tinggi nilainilai tradisional sehingga kehidupan kelompok terpusat pada tradisi kebudayaan yang telah dipelihara secara turun-menurun.

Kelompok kekerabatan kemudian terlihat mulai bergeser pasca Arab Spring, maka kelompok tersebut berkembang menjadi suatu kelompok yang heterogen dari sisi silsilah keturunan yang sebelumnya sangat dipuja oleh masyarakat Arab.

Munculah kelompok-kelompok okupasional yang terdiri dari kalangan professional yang memiliki tujuan dan konsep yang mampu mempengaruhi kelompok keturunan tersebut dan didukung oleh kelompok volunteer yang masuk kelompok yang telah mantap dan diakui oleh masyarakat umum.

Tatanan baru yang merupakan harapan utama dari dinamika sosial ini masih jauh dari harapan, pembahasan di atas menggambarkan bahwa negara-negara di kawasan Timur Tengah seyogyanya memulai kembali dari awal, demi sebuah kebudayaan yang mapan dalam menjaga stabilitas kehidupan masyarakat di kawasan tersebut, maka perlu dilakukan langkah-langkah terobosan guna memperoleh kesepahaman bersama, di mana kesepahaman inilah yang kemudian disebut sebagai pranata yang berlaku dan disepakati bersama oleh seluruh masyarakat. Adapun hal-hal yang harus mulai dicapai adalah:

Nilai dan norma, sebagai sebuah kawasan dengan budaya yang sangat kaya, Arab 
seharusnya kembali memegang lagi prinsipprinsip dari nilai-nilai dan norma-norma yang telah diwariskan oleh Islam yang telah menjadi pemersatu diantara mereka.

Pola perilaku yang menjadi prosedur umum merupakan sebuah terobosan terpenting untuk menstabilkan kembali kawasan ini, seperti Islam selalu mengajarkan untuk selalu bermusyawarah dalam setiap mengambil keputusan bersama untuk dapat dijalankan sebagai panduan dalam kehidupan sehari-hari.

Sistem hubungan, yaitu institusi-institusi yang berlaku dan digunakan untuk melaksanakan perilaku sesuai dengan prosedur umum yang berlaku dan disepakati oleh masing-masing pihak, sebenarnya Liga Arab sebagai organisasi kawasan di negara-negara Arab seyogyanya mampu dan mau berkontribusi dalam menjaga dan mengawal stabilitas keamanan di kawasan yang sampai saat ini masih menjadi prioritas.

\section{KESIMPULAN}

Arab Spring bukanlah sebuah fenomena baru di kawasan timur tengah, hal ini sudah terjadi sejak zaman pra-Islam (jahiliyah) di mana sering terjadi peperangan dan perebutan kekuasaan dan wilayah diantara mereka, akan tetapi terjadi pergeseran budaya dalam masyarakat Arab di sini yaitu kelompok kekerabatan yang merupakan ciri kelompok mereka sering disebut juga dengan kabilah telah bergeser menjadi kelompok okupasional yang lebih heterogen dengan kesamaan tujuan yang mampu mempengaruhi dan menggabungkan kelompok - kelompok tradisional.

Gerakan inilah yang kemudian menjadi dinamika kelompok sosial dengan kekuatan yang sudah disusun dalam kurun waktu tertentu karena masing-masing kelompok mempunyai rekam jejaknya masing-masing.

Tetapi untuk merumuskan tatanan baru yang sangat diharapkan pasca Arab Spring perlu untuk kembali melihat rumusan pranata masyarakat Arab setidaknya dalam makalah ini diusulkan tiga langkah yang diharapkan mampu mengembalikan stabilitas kawasan ini yaitu nilai dan norma, pola perilaku dan sistem hubungan yang sangat diharapkan Liga Arab mampu dan mau mengambil peranan ini sebagai institusi.

\section{DAFTAR PUSTAKA}

[1] Ahmad Sahide. 2013. Konflik Syi'ahSunni Pasca-The Arab Spring. KAWISTARA. Vol. 3 No. 3. Jakarta: UGM

[2] Bagir, Zainal Abidin et al.. 2005. Integrasi Ilmu dan Agama: Interpretasi dan Aksi. Bandung: PT Mizan Pustaka

[3] Benedict, Ruth. 2005. PATTERNS OF CULTURE. New York: Houghton Mifflin Company

[4] Rubin, Barry. 1998. The Geopolitics of Middle East Conflict and Crisis. Meri: Middle East Review of International Affairs. [Online] MERIA JOURNAL, (Diakses pada 28 Oktober 2015)

[5] Hardiman, F. Budi. 2007. Filsafat Fragmentaris Deskripsi, Kritik dan Dekontruksi. Yogyakarta: Penerbit Kanisius

[6] Hitti, Philip K..2006. History of The Arabs. Jakarta: Serambi.

[7] Horton, Paul B., Chester L. Hunt. 1980. Sociology. Edition 5. Pennsylvania: Mc Graw-Hill

[8] Huntington, Samuel P.. 1996. THE CLASH OFCIVILIZATIONS AND THE REMAKING OF WORLD ORDER. New York: Simon \& Schuster Paperbacks

[9] Jatmika, Sidik. 2009. Urip Mung Mampir Ngguyu. Yogyakarta: Kanisius

[10] Rangkuti, Freddy. 2011. SWOT Balanced Scorecard Teknik menyusun strategi korporat yang efektif plus cara mengelola kinerja dan risiko. Jakarta: PT Gramedia Pustaka Utama

[11] Sahrasad, Herdi. 2012. ARAB SPRING: Risalah Studi Timur Tengah. Lembaga Studi Agama dan Filsafat \& Media Institute

[12] Sihbudi, Reza. 2007. MENYANDERA TIMUR TENGAH. Bandung: PT. Mizan Publika

[13] Sukardi, Imam dkk. 2003. PILAR Islam bagi Pluralisme Modern. Solo: tiga serangkai

[14] http://kamusbahasaindonesia.org/. (Diakses pada 24 Oktober 2015) 